\title{
Thai Musical Instruments: Development of Innovative Multimedia to Enhance Learning among Secondary Level Education Students (M.1 to M.3) in Bangkok
}

\author{
Prapassorn Tanta-o-Pas ${ }^{1}$, Songkoon Chantachon ${ }^{1} \&$ Marisa Koseyayothin ${ }^{2}$ \\ ${ }^{1}$ The Faculty of Cultural Science, Mahasarakham University, Khamriang Sub-District, Kantarawichai District, \\ Maha Sarakham, Thailand \\ ${ }^{2}$ Kanchanapisek Non-Formal Education Centre (Royal Academy), Salaya Sub-District, Bhuttamonthon District, \\ Nakhon Pathom, Thailand \\ Correspondence: Prapassorn Tanta-o-Pas, The Faculty of Cultural Science, Mahasarakham University, \\ Khamriang Sub-District, Kantarawichai District, Maha Sarakham 44150, Thailand. E-mail: \\ aunji2000@gmail.com
}

Received: June 4, 2013 Accepted: July 26, 2013 Online Published: September 29, 2013

doi:10.5539/ass.v9n13p163 URL: http://dx.doi.org/10.5539/ass.v9n13p163

\begin{abstract}
Thai music is a part of Thai cultural heritage that has been accumulated and inherited over time. Value should be placed on the knowledge and conservation of Thai music so that it may exist in modern Thai society. This research is a cultural research with three aims: a) to study the historical background of Thai music; b) to study the problems, requirements and methods of learning for Thai music; c) to develop innovative multimedia to enhance learning of Thai music. The results of the research found that Thai music is derived from local Thai wisdom and is a part of cultural heritage that has unique characteristics and formats to clearly indicate its Thai identity. The success of Thai music teaching is dependent on the interest of the students and different forms of multimedia are tools that can create stimulation and enhance learning of the subject. The development of innovative multimedia to increase learning of Thai music among secondary level education students is an important method in safe-guarding this vital part of national cultural heritage for future generations.
\end{abstract}

Keywords: Thai music, multimedia, innovative, creation, society, culture, inheritance

\section{Introduction}

Different forms of art are things that humans created, whether they are paintings, sculpture, handicrafts, performance arts, music or others. They have different aspects of beauty according to the feelings of people. Music is an art form that can be seen in all nationalities and communities, even if those societies are small. Music is related to the auditory nerve, which is the tool for receiving knowledge and translating the meaning of imagination or important thoughts. The sounds that are heard may or may not have meaning, which is similar to the sounds of the spoken word in that the meanings of the sounds differ according to the opinions or emotions of different people (Pukhaotong, 1989, p.9).

Music is an invention of humanity, an art that reveals emotion, thought and beauty. It is also valuable to people as a form of cultural reflection. Music is the only form of art that does not require interpretation because the meaning of the music will appear differently in the minds of the listeners, according to the power of the music to enter the mind. The meaning of individual pieces of music will be differ with the background and experience accumulated by the listeners. Music is thus a tool to express the value of humanity to the listener (Rungrueang, 1990, p.13). Music is a universal language of the planet that people of all nationalities can use to communicate. Music has more positives than negatives and is a tool to nurture the spirit and the mind. It is a way to take care of the physical and mental aspects of the world. Music calms people and is a friend in times of sorrow or loneliness. Music is a way to unite people and express love (Amatyakoon, 1986, p.2).

Music is an important part of national culture. Developed nations have their own national form of music. These national forms differ in style, sound, volume, instruments and methods of play. The characteristics of the music allow the listener to identify the origin of the art. Each nation is proud of its own national music and tries to develop the art form so that it continues in the future. Therefore, the musical culture reveals the development of 
knowledge, thought and belief in each nation (Pukhaotong, 1989, p.5).

Thai music has had a long history since the past. In the time of Prajaoborom Mawongteu Grompraya Damrong Rachanuphap it was discovered that Thai music came from India, which was one of the most important civilizations in the world. Indian culture had a large influence on other countries in Asia, including religion, customs, beliefs and various art forms, especially music, which included methods and instruments. Thai musical instruments are categorized into four groups, according to the method of playing: plucked, bowed, struck and blown. Examples of instruments in each category are grajabpi and jakhe (plucked), saw sam sai, saw duang and saw $u$ (bowed), ranat, khlong, khong, thon, rammana and taphon (struck) and pi and khlui (blown). The Indian instruments were also categorized into four groups: string instruments (chordophones), wind instruments (aerophones), membranophones and idiophones. This is different to the opinion of Pradit Intanin (1983, p.10), which was that Thai music came from the wisdom of Thai people and developed with the people after they moved South of China. In this way, music is part of national heritage and is why each nation will have a unique musical identity, which can be observed in the unique names for the Thai musical instruments, such as groh, krong, krab, chap, ching, pi, khlui, khong and glong. Some Thai musical instruments were created by Thai people, while others were adopted from other cultures (Todsaporn et al., 2004, p.533).

Montri Dramote (1969, pp.240-2) explained the characteristics of Thai music in the first book of the Thai Junior Encyclopedia. Dramote stated that Thai people have known how to create music and have enjoyed music for a long time. Even uncivilized or savage communities knew how to make a variety of sounds that people considered melodious. Over time, when Thai people immigrated into the Indo-Chinese region, they met with Indian style culture, particularly Indian musical instruments, which the Mon and Khmer people had already accepted before the arrival of the Thai people. For this reason, the Thai nation, which already had musical habits, incorporated the Indian style (mixed with Mon and Khmer forms) into their own musical structure. This meant for the creation of more musical instrument varieties, such as pin, sang, pi-chanai, bantoh, krajab-pi and jakhe. This corresponds to the research of Panya Rungrueang (1989, p.3), which concluded that Thai music has unique characteristics of sound and rhythm, as well as the sounds of the individual instruments, tones, musical expressions. It can thus be said that Thai music is extremely unusual and stranger than other musical varieties. Thai music has basic principles that cannot be compared to the musical principles of other nations, especially in terms of scale, melody and emotion (Naksawat, 1987, p.2). Thai music is thus one form of Thai culture that the people created. It reveals the cultural identity of the people and is a part of global social heritage that has been passed on to the present day (Sowat, 1995, p.1).

In the development plan for education, religion and culture, the government has strategic policies for sponsorship and support of music conservation and inheritance. There are four defined plans, which are promotion and sponsorship of education, investigation, research and knowledge. These four policies are to ensure that culture is able to exist in harmony with the ever changing modern world and be inherited by future generations.

The teaching of Thai music is important within Thailand and this part of the national cultural heritage must be maintained and inherited so that it may continue to flourish. Past inheritance of Thai music was voluntary. The students were required to directly visit the instructor's home. Transmission of local wisdom was in the form of mook-ba-ta, an ancient method of teaching by oral account with no written records that emphasized learning by performance. Nowadays the subject of Thai music has been incorporated as part of the basic central curriculum, which makes it compulsory for students in the education system to study Thai music, according to the criteria indicated for each level. The emphasis of knowledge is on musical theory and the transmission of knowledge is systematic between one teacher and one class (fifty pupils). Problems with the music curriculum arise from changes to society. The study and teaching of music must be made suitable for the main objectives of the learners. Thai music is a subject where motivation and stimulation are necessary for pupils to receive knowledge. This is especially the case for compulsory aspects of the local curriculum at the educational institutions. Therefore, the use of multimedia is something that can create stimulation, interest and enhance learning in another way.

There are many ways that technology can be used in the music lessons, such as the application of programs like Truebook and Author Ware. Nowadays, computer technology has an important role in the everyday life of humans and is used in all aspects of education to develop the quality of teaching. This is known as Computer Assisted Instruction (CAI). The characteristics are unlike books, slides or projections because the students have an interactive role. The computer enables the student to learn at their own pace. Faster students do not need to wait for slower students, and slower students do not get left behind by faster students (Sutkaew, 1995, p.116). The use of computers in education leads to fast development and the computers are thus responsible for alterations to the method of knowledge inheritance (Hinkaew, 2002, p.3). The use of computers, multimedia and the internet also makes the knowledge of Thai music accessible to a wider audience and provides an opportunity 
for all people, domestically or internationally, to study the art.

The development of innovative multimedia to enhance learning of Thai music among secondary level education students (M.1 to M.3) has value and benefits that can be used because it can enable the fulfillment of learning from direct instruction and independent study. This includes the publicity and conservation of local Thai wisdom, which is a part of the national cultural heritage for future generations.

It is thus possible to see that the conservation and promotion of Thai art culture can be done in many ways. However the primary objective must be to adapt the culture for lasting popularity and inheritance. For this reason, the researchers saw the benefit of studying this part of local Thai wisdom and cultural heritage that should be passed on to future generations as part of the national identity. The researchers were thus interested in investigating the development of innovative multimedia to enhance learning of Thai music among secondary level education students (M.1 to M.3) in Bangkok.

\section{Research Aims}

This research had three primary aims: a) to study the historical background of Thai musical instruments in four categories: string ('plucked' \& 'bowed') percussion ('struck') and wind ('blown'). This includes the study of local wisdom related to Thai music performances and the conditions and problems with the inheritance of local wisdom; b) to study the problems, requirements and methods of learning Thai music among secondary level education students (M.1-M.3) in Bangkok; c) to develop innovative multimedia to enhance learning of Thai music among secondary level education students (M.1-M.3) in Bangkok.

\section{Research Methodology}

This is a qualitative research that used both documentary study and field research. The research was conducted in line with the three research aims. Data collection tools were interview, survey, focus group discussion and workshop. There were three steps to the research method. The first step was the use of document research, survey and interview to gather evidence relating to the history, knowledge, current conditions of and problems with Thai music and instruments. The second step was the development of innovative multimedia to enhance learning of Thai music among secondary level education students. This stage included collection and preparation of data, development of innovative multimedia and creation and implementation of a model. The third step was the quality check and evaluation of innovative multimedia created during the research. Data from field research was collected by interview, survey, focus group discussion and workshop. Bangkok was selected as the research area as it is the area in Thailand with the largest number of education establishments. One-hundred and seventeen government schools are situated in Bangkok but the researchers selected the sample population of three schools using a purposive sampling technique with the following criteria: a) government schools with secondary level education in the Bangkok education area; b) a large school with over two thousand pupils; c) a school with skilled and experienced Thai music teachers and where it was possible to continually consult the students; d) schools that had equipment and classrooms prepared for the introduction of innovative multimedia. The population was comprised of thirteen key informants (four experts and the directors, academic assistant directors and heads of the art departments at each of the three schools), sixty-three casual informants (three teachers and sixty students) and sixty general informants (parents \& guardians). The research began in September 2011 and finished in March 2013. The data was validated using a triangulation technique and analyzed according to the three research aims. The results of the research were presented using a descriptive analysis.

\section{Results}

\subsection{The Historical Background of Thai Music}

Thai music is derived from the knowledge that has been accumulated and inherited from ancestral wisdom. Thai music has attributes and form that clearly reveal Thai identity. These include the shapes of the instruments, levels of sound and timing, tone and musical expressions. Thai music is science and art, cause and result that can be explained and is related to connection and combination with other cultures. These cultures were adapted to be suitable for Thai culture, customs and traditions. Thai people have created their own instruments or adapted those from other cultures for many centuries. Thai instruments fall into four categories, according to the method of playing: plucked, bowed, struck and blown. The plucked instruments were the first to be developed and can be broken down into three sub-categories, which are instruments made from wood, instruments made from metal and instruments made from leather. The next instruments to be developed were the blown instruments, which can be further divided into instruments requiring use of the tongue and instruments blown without the tongue. The third and fourth categories to be developed were struck and bowed respectively. 
Thai music has constantly been developed and altered due to environmental factors, such as events, the land and social conditions. These developments are visible in Thai music, whether they are related to the instruments, music, performance or any other aspect. Effects from the use of substitute materials in the creation of musical instruments, the planning of regulations and the integration of Thai music and music from other cultures are still visible in modern Thai music. Whether these developments are lasting depends on their acceptance by people in society. Aside from this, the components of Thai music that reveal Thai identity the clearest are Thai musical instruments, Thai music ensembles, the form of Thai music, the form of performance regulations, especially the two methods of separation (by instrument style or by instrument responsibility).

Regarding the inheritance of local wisdom, it was found to be in the form of mook-ba-ta, an ancient method of teaching by oral account with no written records that emphasized learning by performance. The teacher would require their pupil to remember and reproduce. The student must ask questions about musical theory, observe or wait for the instructor to explain. Over time the inheritance form was increasingly planned until it was incorporated into the education system. Models of performance method and teaching standards were adapted for use with the current era. Objectives were also outlined for the study of Thai music, such as for occupational use as a teacher or artist and for development of special ability. Problems with inheritance are derived from the influence of other cultures and changes to society. The development of Thai music in its original form was limited as the knowledge of local wisdom is weak and it was concluded that for the continuation of Thai music inheritance, time had to be allocated in the education system. Thai music was thus made a compulsory subject in the basic curriculum of secondary education. Additional study of Thai music was also made available as part of the curriculum for those students wishing to learn more about the art.

Learning within the curriculum has widened general knowledge about important Thai music theories. Teaching and learning in the schools is between one teacher and one class of approximately fifty pupils. There are also tools to aid the instructor in the teaching of theory and practice, which are currently in the form of various pieces of modern technology. These forms of technology are popular because they can accelerate the learning process and incorporate graphics, text, sound and video. This allows the student to understand the material easily and more conveniently.

\subsection{The Problems, Requirements and Methods of Learning Thai Music among Secondary Level Education Students (M.1-M.3) in Bangkok}

There were two groups of problems with learning Thai music among secondary level education students in Bangkok, which were problems for the instructors and problems for the pupils. The problem for teachers was the lack of time to teach the suggested course material, which is too varied and includes dance and international music. Additionally, the teacher must be responsible for a large number of students as well as the instruction of both theory and practice. For this reason, the teacher is unable to monitor and instruct every pupil as efficiently as they should, particularly during the practical sections of study. Moreover, there is an insufficient number of musical instruments for the number of students. The problem for students is the lack of interest in Thai music, due to the emphasis on theory rather than practice. When students are able to practice, they are forced to play instruments that do not interest them, rather than select the instruments that they wish to use.

\subsection{Development of Innovative Multimedia to Enhance Learning of Thai Music among Secondary Level Education Students (M.1-M.3) in Bangkok}

Innovative multimedia can be used to create stimulating educational resources that enable the swift transfer of knowledge. Innovative multimedia first started to have a role in the classroom in approximately 1997 and at first was only developed with regards print. Developments soon moved to concern images, sounds and motion, which led to increased usage and popularity. This is because the computer was able to help reduce limitations with the inheritance process, increase the variety of inheritance models and enable independent study at school and at home. Multimedia is the term used to describe a variety of different materials, such as still images, motion pictures and sound that are used as intermediaries in the knowledge transfer process. With the introduction of modern technology, multimedia became increasingly more developed and the computer could be used in the creation and control of multimedia to increase efficiency, convenience and popularity.

In the past, if certain media were required for use in the lesson, specific equipment was required to facilitate their use. With the introduction of the computer, this specific equipment became increasingly obsolete and the media was referred to as 'multimedia'. Nowadays, there are two characteristics, which are instructive multimedia with the sole purpose of conveying information and interactive multimedia that provide an opportunity for the learner to participate.

Multimedia can be used for the teaching of Thai music in schools but, with pressure on teachers to cover a 
variety of theoretical and practical material in a limited time-frame, multimedia must be created and adapted to be suitable for the course content. If the multimedia is to boost the efficiency and attraction of the teaching it depends on a number of factors, including correspondence to study material and appropriateness of the situation. Aside from this, the effect of multimedia use also depends on the users. The multimedia must be convenient for use in the workplace and must enable the exchange of questions and responses between the instructor and the student. The multimedia must be tested before and after study to ascertain the effect of the multimedia on the knowledge of the pupils. The students will see the benefits of multimedia in the increased interest value of the material, convenience for independent study and reduction of learning limitations.

During this research, four steps of multimedia development were identified. The first step was collection and preparation of data related to all four categories of Thai musical instrument with regards graphics, text, sound and video. This data was then used to create innovative media and a number of different computer monitors for the presentation of different topics: a) knowledge of Thai music; b) still images and components of Thai musical instruments; c) demonstrative videos of musical performance; d) musical sound recordings; e) tests and quizzes. The second step was the development of innovative multimedia using programming language in the program Microsoft Visual Basic, version 6.0 service pack 6. The third step was the establishment of a development model and its implementation in the schools. The final step was the evaluation of the multimedia in a workshop, which found that the new multimedia promoted knowledge transfer and were suitable for use in the classroom and for independent study. They were also found to be another method of helping the conservation and support of local Thai wisdom surrounding Thai music. The method of development was compatible with ever-changing modern technology.

\section{Discussion}

\subsection{The Historical Background of Thai Music}

The results found that Thai music was at least partly created within Thai society by Thai people and spread throughout the nation. This is in line with the diffusion theory of Franz Boas, which stated that the aspects of one culture spread by acceptance and adaptation in the sphere of other cultures. The evidence surrounding Thai music also corresponds to the development of cultural area theory by Clark Wissler and Alfred Kroeber. The argument holds that a territorial area is home to a uniform culture, which began at an origin and spread to all areas within reach. Culture is dependent on the movement of humanity. Where humans move, so culture moves with them (Wannasiri, 2007, pp.85-86). This is also dependent upon four factors, which are geographical area, economy, society and communication.

This research also used the theories of ethnomusicology promoted by Jaap Kunst. This term is used in place of 'comparative music' and refers to study of indigenous music, Western music and contemporary music that has been inherited by the mook-ba-ta method. This is an anthropological method of examining music in terms of its social and cultural context.

Considering these two theories, it can be concluded that Thai music was influenced by the cultures of other groups living in the same geographical area, especially India and China, who had a long and ancient historical civilization. In this area, the acceptance of Indian music occurred with relation to ceremonies, beliefs and religion. When aspects of these three spheres were adopted, so to was the music associated with them. Chinese music was accepted due to its close relationship with Thailand in terms of geography, national beliefs, immigration, musical reputation and method of play. Problems that subsequently developed with the inheritance of Thai music arose from changing conditions of society and the inability of these fused musical cultures to adapt.

\subsection{The Problems, Requirements and Methods of Learning Thai Music among Secondary Level Education Students (M.1-M.3) in Bangkok}

Regarding the methods of learning management, the researchers studied the learning theory of Benjamin $\mathrm{S}$ Bloom. In order for the learning process to result in success, Bloom's concept stated that clear objectives must be defined before study has begun, activities must be lucid and evaluation must be correct. Bloom said that humans would develop knowledge in three spheres: intelligence, body and mentality. This knowledge was, according to Bloom, on six levels: knowledge, comprehension, application, analysis, synthesis and evaluation. The researchers also used the learning process theory of Robert M. Gagne, which identified three crucial components of learning for the successful transfer of knowledge: learner, stimulus and response. Gagne's theory corresponds to this research because Thai music is a compulsory subject in the Thai education system. This mandatory nature causes students to lack interest and it is thus necessary to create new stimuli to attract the attention of the pupils to generate a more positive response. Additionally, the researchers studied the information processing theory in 
developmental psychology. This theory states that human work is similar to the work of a computer. The information theory holds that the human mind has ways to receive data, a short-term memory for manipulating data and a long-term memory for storing data. The principle of learning and teaching in this theory is that if people have access to knowledge and data related to a topic, they will become more attentive in that topic and continually develop.

\subsection{Development of Innovative Multimedia to Enhance Learning of Thai Music among Secondary Level} Education Students (M.1-M.3) in Bangkok

For the development of innovative multimedia to enhance learning of Thai music among secondary level education students (M.1-M.3) in Bangkok, the following components of the operational procedure were identified: a) the step of collaboration and preparation of data; b) the step of developing innovative media; c) the step of establishing and using a model. The innovations made to multimedia can increase stimulation for students and have a positive effect on their interest levels. This is in correspondence to the research of Konggrit Tanagarn (2006, p.100), which found that students using multimedia in their studies had greater success after the lesson than students who did not use multimedia.

This research agrees with various concepts of development, especially those concerned with social change. Importantly, the researchers studied theories involving social change, so to adapt the inheritance process for Thai music to be compatible with the current era. This relates to the social judgment theory of Sherif, Sherif and Hovland. The theory asserts that society has three responses to a phenomenon: rejection, acceptance and non-commitment. The steps in the response of acceptance are awareness, interest, evaluation, trial and adoption. If technology is used to secure the interest of students in Thai music inheritance, then the latter stages will follow.

The researchers also studied the development of innovations theory by Everett M Rogers. The theory stated that adoption of innovations was dependent on the individual (innovators, early adopters, early majority, late majority \& laggards), society, communication, the innovation itself and the time period. The creation of innovative multimedia for the learning of Thai music must therefore correspond to all students, fast and slow in the current society by using effective transmission methods in a suitable time frame.

The development of innovative multimedia to enhance learning of Thai music among secondary level education students (M.1 to M.3) has value and benefits that can be used because it can enable the fulfillment of learning from direct instruction and independent study. This includes the publicity and conservation of local Thai wisdom, which is a part of the national cultural heritage for future generations.

\section{References}

Amatyakoon, P. (1986). Music Research. Bangkok: Siam Smile Publishers.

Dramote, M. (1969). Thai Music. Bangkok: Thai Wattanapanich.

Hinkaew, P. (2002). Results of using computer multimedia courses on the web on the topic of internet technology for lower secondary level students. Srinakharinwirot University: Srinakharinwirot University Press.

Intanin, P. (1983). Thai Music Periscope. Chonburi: Kamonsin Publishers.

Naksawat, U. (1987). Theory and Practice of Thai Music in the First Area. Bangkok: Jaroen Printers.

Pukhaotong, S. (1989). The way to Thai Music. In Music Road, 1(1), 66.

Rungrueang, P. (1990). Reading and listening to Thai music. Bangkok: Chulalongkorn University Press.

Sowat, B. (1995). Analysis of style in the music of Khek Mon Bang Kun Prom. Bangkok: Mahidol University.

Sutkaew, P. (1995). Classrooms in the year 2000. In Science MC, 23(3), July-September.

Tanagarn, K. (2006). Development of MMCAI for Thai dance and music for upper secondary level students. Bangkok: King Mongkut's Institute of Technology.

Todsaporn et al. (2004). Musical performance art for first level Matthayomsuksa students. Bangkok: Aksorn Jaroentat Plc.

Wannasiri, N. (2007). Humanity, Society and Culture. Bangkok: Tana Press Ltd.

\section{Copyrights}

Copyright for this article is retained by the author(s), with first publication rights granted to the journal.

This is an open-access article distributed under the terms and conditions of the Creative Commons Attribution license (http://creativecommons.org/licenses/by/3.0/). 